\title{
Da ferrovia ao museu, uma viagem pelas memórias que \\ constroem as identidades de Peirópolis (1970-2018)
}

\section{Karen Pereira Freitas Silva Laura de Barros Pereira}

DOI: 10.11606/issn.2318-8855.v10i1p360-389

Resumo: Peirópolis, o bairro rural uberabense, além do bucolismo, exala História, seja em suas memoriais edificações tombadas, seja no ritmo dos moradores que não negam uma boa prosa. A inquietação que norteou a pesquisa foi: quais identidades estão vinculadas a Peirópolis? Essa demanda se fez necessária em função da carência de pesquisa histórica específica sobre o local. Isso porque o levantamento dos trabalhos que tratam de Peirópolis revelou que as pesquisas envolvendo o bairro concentram-se nas áreas arquitetônica, urbanística ou geográfica, não tratando, portanto, das relações historicamente estabelecidas para a configuração do lugar e suas identidades. As fontes utilizadas são de origem documental e oral, sendo que, cada uma recebeu o tratamento inerente à sua natureza. O intuito foi remontar a história de Peirópolis, no recorte temporal estabelecido, através das publicações formais, das memórias dos moradores e das transformações que ocorreram na comunidade de modo a compreender os aspectos que compõem suas identidades.

Palavras-chave: Identidade; Memória; Peirópolis. 


\section{artigos}

\section{Karen Pereira Freitas Silva / Laura de Barros Pereira}

\section{Introdução}

Esta pesquisa refere-se à história recente do bairro rural de Peirópolis, em Uberaba - MG. Sua motivação está no desejo de compreender os processos históricos que marcaram a trajetória do lugar e ajudaram a configurar suas identidades. Atrelado a isso, está a constatação da escassez de pesquisas históricas que debatem ou mencionam o bairro e sua importância para o Triângulo Mineiro. As poucas pesquisas disponíveis reconhecem a importância paleontológica, arquitetônica, geográfico-urbanística do lugar, mas não buscam compreender as relações sociais estabelecidas entre os sujeitos que ali habitam e como se constituem as identidades locais.

A história de Peirópolis é rememorada, geralmente, a partir da chegada da estação férrea e da atuação do imigrante espanhol Frederico Peiró, ambos eventos da transição do século XIX para o século XX. O imigrante espanhol administrou e posteriormente comprou uma caieira na região de Paineiras - atual Peirópolis - na década de 1910. Associado a outros imigrantes, como o também espanhol Maximino Alonso, fomentou o desenvolvimento do bairro rural. Entretanto, o recorte temporal adotado para esta pesquisa se deu a partir de 1970, quando a ferrovia encerrou suas atividades. Embora, desde seus eventos iniciais, a história do lugar seja rica e inusitada, a periodização adotada neste estudo congrega as transformações que formam e consolidam as identidades de Peirópolis.

A pesquisa intenciona compreender os elementos que fomentam as identidades através dos vestígios selecionados e reconstituir a história recente do bairro. O intuito é construir uma narrativa histórica que considere as memórias dos moradores e como significam o pertencimento ao lugar. Assim, "a história como 


\section{artigos}

\section{Da ferrovia ao museu, uma viagem pelas memórias que constroem as identidades}

de Peirópolis (1970-2018)

operação será tentar, de maneira necessariamente limitada, compreendê-la como a relação entre um lugar (...), procedimentos de análise (...) e a construção de um texto" (CERTEAU, 2017, p.46, grifo do autor).

As fontes eleitas para esta pesquisa foram de natureza documental - Atas da Câmara Municipal de Uberaba -, impressa - Jornal Lavoura e Comércio - e oral entrevistas com moradores do bairro. Inicialmente, é primordial a disponibilidade e acesso aos vestígios. Nesse sentido, as fontes documentais e impressas estavam disponíveis no Arquivo Público de Uberaba (APU), e as fontes orais foram possibilitadas por meio de entrevistas concedidas por alguns moradores, após apresentação do projeto à comunidade. Uma outra premissa, é em que medida as fontes atendem ao problema de pesquisa. Por esse aspecto, os vestígios documentais, impressos e orais demonstram, consecutivamente, como o poder público enxerga Peirópolis, como o bairro foi divulgado e quais as memórias da comunidade sobre o lugar.

\section{Um pouco do contexto histórico de Peirópolis}

Peirópolis é um bairro rural de Uberaba, Minas Gerais, situado a $20 \mathrm{~km}$ do centro da cidade, composto por uma população marcada pela diversidade social, econômica, cultural e religiosa. Atualmente, o bairro é conhecido como um centro de pesquisas e referência paleontológica no Brasil.

O lugar sofreu impactos decorrentes das transformações nacionais do final do século XIX, como a chegada de imigrantes europeus e o ideário do progresso na figura da ferrovia. Os cafeicultores paulistas substituíram a mão de obra escravizada pela mão de obra de imigrantes livres. Outra tática utilizada, foi a de se associarem na 


\section{artigos}

\section{Karen Pereira Freitas Silva / Laura de Barros Pereira}

criação de estradas de ferro. Conforme Paulo Oliveira (2008, p.205), "a questão da mão de obra e do transporte foi sanada, culminando na formação do complexo cafeeiro paulista". A ligação entre Paineiras, atualmente Peirópolis, e o complexo cafeeiro paulista se deu pela Companhia Mogiana de Estradas de Ferro. Em 1889, ela estendeu seus trilhos para além do Rio Grande. Tal linha ficou conhecida por linha do Catalão, que passava por várias estações, sendo que a última delas era em Uberaba. Deste prolongamento, Paineiras recebeu sua própria estação. Posteriormente, a ferrovia chegou a São Pedro de Uberabinha - atual Uberlândia - e Araguari.

Em 1896, o imigrante espanhol Frederico Peiró chegou à região, e em 1890, iniciou as atividades de mineração de calcário para a fabricação da cal. Ele construiu também armazéns que estocavam arroz, milho e feijão. Alimentos que eram produzidos na região e despachados por via férrea com destino a São Paulo e Rio de Janeiro. Peiró faleceu no ano de 1915 e, em 1924, a estação denominada Paineiras passou a se chamar Peirópolis em sua homenagem (RIBEIRO, 2014).

Em meados de 1940, por meio de uma correção realizada nos trilhos da ferrovia e pela atividade mineradora, foram encontrados no local fósseis datados de 80 a 65 milhões de anos. O achado culminou na transformação a longo prazo de Peirópolis em um sítio paleontológico e em centro de referência e de pesquisa na área de paleontologia no Brasil e no mundo (RIBEIRO; CARVALHO, 2007). A notícia dos fósseis encontrados acarretou visibilidade, despertando atenção de pesquisadores e estudiosos da área. Um deles, o paleontólogo Llewellyn Ivor Price, foi convidado a se responsabilizar por conduzir as pesquisas e escavações realizadas em Peirópolis, localizado na Serra da Galga (RIBEIRO; CARVALHO, 2007).

Após um grave acidente na ferrovia em setembro de 1970, a atividade 


\section{artigos}

\section{Da ferrovia ao museu, uma viagem pelas memórias que constroem as identidades}

de Peirópolis (1970-2018)

ferroviária foi encerrada no bairro, interferindo na movimentação de pessoas e produtos. Com o fechamento da ferrovia e da empresa que fabricava cal, Peirópolis passou por um período de crise econômica e, consequentemente, ocorreu também a migração de grande parte da população que vivia ali. Assim o bairro vivenciou um momento de estagnação, considerando que com a estação havia um grande fluxo de pessoas e de mercadorias, que movimentava o local e sua economia. A estação foi desapropriada em 1986 e esteve em estado de abandono até 1992 (ESTAÇÕES FERROVIÁRIAS DO BRASIL, 2017).

Na década de 1980, foi criada pela comunidade uma organização não governamental, que buscava melhores condições de tratamento dos fósseis. Tal organização, denominada de Associação dos Amigos do Sítio Paleontológico de Peirópolis, era composta por moradores, representantes e defensores das causas científicas. O trabalho do grupo foi primordial no que tange à escavação e manutenção dos fósseis em Peirópolis, uma vez que por meio de ações judiciais, conseguiu encerrar as atividades de uma mineradora na região. Além disso, com intensa dedicação, o grupo de associados lutou pela desapropriação e criação de um espaço para estudo e exposição dos fósseis no bairro. Deste modo, em 1992 houve a inauguração do Centro de Pesquisas Paleontológicas Llewellyn Ivor Price, que constitui também o Museu dos Dinossauros, no prédio da antiga estação férrea, tombada e restaurada.

A implementação do museu visava ainda a aproximação dos moradores e do público em geral com as questões paleontológicas, valorizando uma identidade local e conscientizando sobre a importância do trabalho desenvolvido. Atualmente os funcionários do Centro de Pesquisas Paleontológicas Llewellyn Ivor Price e do Museu 


\section{artigos}

\section{Karen Pereira Freitas Silva / Laura de Barros Pereira}

dos Dinossauros são em sua grande maioria moradores da região, o que demonstra o fortalecimento do vínculo entre a população com as questões paleontológicas (RIBEIRO; CARVALHO, 2007). Ademais, o Centro de Pesquisas Paleontológicas Llewellyn Ivor Price também constitui o Complexo Cultural e Científico de Peirópolis (CCCP), que foi inaugurado em 2010, pela Universidade Federal do Triângulo Mineiro (UFTM). Ele desenvolve atividades de ensino, pesquisa e extensão, sendo um centro de referência nacional em paleontologia.

A economia de Peirópolis gira em torno do Turismo proporcionado pela consolidação do lugar como espaço de pesquisa e museu paleontológico. As atividades adjacentes como a gastronomia típica mineira e as rotas de ecoturismo giram em torno da centralidade do Museu como espaço de atração, seja pelo turismo eventual, seja pela promoção do espaço como ambiente de educação patrimonial paleontológico. A movimentação econômica se dá, aos finais de semana, nos restaurantes locais, pousadas e na venda de doces artesanais. Entretanto, a dinâmica ao longo da semana se configura de forma diferente: a movimentação turística é reduzida e os restaurantes não abrem. O trânsito de pessoas se reduz às atividades cotidianas do bairro, como a escola, os trabalhadores locais, aos pesquisadores e, frequentemente, ônibus escolares com estudantes que visitam o Museu e o CCCP.

Diversas memórias e diferentes identidades através da oralidade e do registro escrito

A fim de compreender quais identidades estão vinculadas à Peirópolis, considerando que as pesquisas não abordam tal temática, a composição de uma narrativa histórico-científico sobre o bairro e os sujeitos que lá habitam se tornou pertinente. Para tanto, buscamos debater em que medida as memórias veiculadas 


\section{artigos}

\section{Da ferrovia ao museu, uma viagem pelas memórias que constroem as identidades}

de Peirópolis (1970-2018)

pelos habitantes locais estavam em diálogo com as fontes manuscritas e impressas que tratam do registro cotidiano histórico da localidade, bem como as múltiplas identidades plasmadas por essas memórias ativas na comunidade.

No que tange ao conceito de memória, foi necessário entender como esse conceito, amplamente debatido na história e na filosofia subsidiaria os procedimentos de análise do material oral coletado nas entrevistas com os moradores. Compreendendo a memória como uma formulação dinâmica que envolve aspectos subjetivos e sociais, trouxemos para a análise a abordagem do filósofo francês Paul Ricoeur, de base hermenêutica, herdeiro da fenomenologia husserliana. Tendo em vista que seus argumentos e considerações na obra $A$ memória, a história, o esquecimento (2007), fornecem o substrato necessário para o debate dessa dinâmica na reflexão sobre a memória na pesquisa historiográfica. Sobre a memória pessoal e coletiva, o pensador evoca quatro distintas teorias, formuladas por Santo Agostinho, John Locke, Edmund Husserl e Maurice Halbwachs.

Há duas polaridades em se tratando da concepção de memória apresentada pelo filósofo. Alguns dos teóricos citados defendem a memória subjetiva, enquanto outros, defendem a constituição da memória através de uma coletividade. Por trabalhar com fontes orais, a pesquisa demandou a compreensão de como qualificar conceitualmente as lembranças compartilhadas pelos entrevistados, a fim de identificar nelas padrões capazes de definir o sentimento de pertencimento comum ou diverso com relação à Peirópolis e seu passado recente.

De acordo com Ricoeur (2007), é na memória individual que se busca marcas do aspecto social. Há uma relação intermediária entre os pólos da memória que estabelece uma ponte de troca das lembranças individuais e coletivas. 


\title{
artigos
}

\section{Karen Pereira Freitas Silva / Laura de Barros Pereira}

\begin{abstract}
Não existe, entre os dois pólos da memória individual e da memória coletiva, um plano intermediário de referência no qual se operam concretamente as trocas entre a memória viva das pessoas individuais e a memória pública das comunidades às quais pertencemos? Esse plano é o da relação com os próximos, a quem temos o direito de atribuir uma memória de um tempo distinto. Os próximos, essas pessoas que contam para nós e para as quais contamos, estão situados numa faixa de variação das distâncias na relação entre o si e os outros. Variação de distância, mas também variação de modalidades ativas e passivas dos jogos de distanciamento e de aproximação que fazem da proximidade uma relação dinâmica constantemente em movimento: tornar-se próximo, sentir-se próximo. Assim, a proximidade seria a réplica da amizade... (RICOEUR, 2007, p.141).
\end{abstract}

Nesse sentido, a pesquisa realizada com os moradores do bairro, foi baseada na tríplice atribuição de memória sugerida por Ricoeur. No contexto apresentado, os moradores entrevistados ocupam o papel do eu, agentes de suas próprias rememorações; a comunidade do bairro são os próximos; e os (as) escritores (as) da História, são os outros, que recebem essas memórias e as tratam como fontes no intuito de produzir historiografia.

Em tal perspectiva, após pensar o conceito de memória, tornou-se pertinente responder à questão: Quais identidades estão ligadas à Peirópolis? Para tanto, foi preciso recorrer ao debate extenso sobre a constituição histórica das identidades e o seu constante refazer-se embasados no horizonte teórico proposto pela obra $A$ identidade cultural na pós-modernidade (2006) do sociólogo britânico-jamaicano Stuart Hall. Após a análise de entrevistas realizadas no bairro, percebeu-se a existência de distintas identidades presentes ali, que foram se modificando e se reconstituindo de acordo com os acontecimentos históricos da região.

Hall (2006), afirma haver, nas sociedades do final do século XX, uma crise de 


\section{artigos}

\section{Da ferrovia ao museu, uma viagem pelas memórias que constroem as identidades}

de Peirópolis (1970-2018)

identidade. Partindo do pressuposto de que as identidades modernas estão sendo descentradas, ou seja, fragmentadas, devido às mudanças estruturais, tais como noção de classe, raça, etnia ou gênero. O autor ainda sugere, que "o sujeito previamente vivido como tendo uma identidade unificada, está se tornando fragmentado; composto não de uma, mas de várias identidades" (HALL, 2006, p.12).

A partir das fontes orais coletadas, concluiu-se que o bairro uberabense é composto por diversas expressões identitárias. Tal pluralidade acontece devido a transformações ocorridas no lugar, que foram detectadas no recorte temporal de 1970 até 2018. Desde a implementação da ferrovia; sua desativação; a extração da cal; a paleontologia; e a chegada da UFTM, a comunidade vem se modificando a cada nova alteração estrutural.

A História Oral é uma vertente da História amplamente utilizada e debatida na atualidade, seja na constituição da fonte (transcrição de entrevistas), seja nos métodos de análise. "Ela consiste na realização de entrevistas gravadas com indivíduos que participaram de, ou testemunharam, acontecimentos e conjunturas do passado e do presente" (ALBERTI, 2018, p.155). Além do cunho disciplinar, ela pode ser observada e compreendida em outras duas perspectivas: a postura técnica, que envolve gravar a entrevista e arquivá-la; e a história oral como metodologia. Isto é, ela se define como normas e ordenação de processos de trabalho em quaisquer áreas de pesquisa. Portanto, as três possibilidades foram consideradas e subsidiam as reflexões deste trabalho.

Em seu cerne, a História Oral carrega, em grande medida, aspectos da memória do sujeito, de natureza individual e coletiva. O relato de um determinado evento, de um sujeito a outro, possui um intuito memorial, ou seja, manter uma determinada 


\section{artigos}

\section{Karen Pereira Freitas Silva / Laura de Barros Pereira}

memória ativa, sem que ela caia no esquecimento. Deste modo, a oralidade possui em si uma capacidade de reprodução e manutenção da memória.

Por se tratar de um vestígio produzido, o tratamento das fontes orais demanda um método de cuidado redobrado, de modo que não ocorra equívocos na interpretação e em seus usos. Em uma análise externa-interna das fontes, é preciso, inicialmente, ponderar as condições e contextos de produção do vestígio. Em seguida, compreender a entrevista para além de um relato biográfico. É necessário entendê-la como um relato resultante de uma ação constituinte de uma memória. Outro aspecto primordial para o pesquisador é desconstruir a tendência natural de lidar com a entrevista como uma retrospectiva dos fatos. Isso porque os relatos da entrevista são eventos passados, que são narrados pelo entrevistado com significados e atribuições de valores do presente.

Foi pensando nesses conceitos que as fontes orais foram elencadas para a pesquisa. A seleção de entrevistados reuniu nove moradores do bairro. Dentre eles, havia representantes de diversos lugares sociais, considerando que o intuito era compreender os grupos existentes na comunidade, bem como suas identidades e suas perspectivas sobre as transformações do lugar. Além disso, ao captar diversos olhares e memórias sobre as mudanças no bairro, foi possível compreendê-las em uma maior dimensão. Estes olhares possibilitados pelas fontes orais concedem aos (as) historiadores (as) minúcias e subjetividades que outras fontes não alcançam.

Munidos de um roteiro de perguntas e um celular com gravador, a tutora e os (as) discentes coordenaram os processos de entrevistas, gravações e transcrições. No roteiro norteador das entrevistas, além de se apresentar, os (as) entrevistados (as) foram inquiridos (as) em perguntas sobre a formação de Peirópolis, sua trajetória - 


\section{artigos}

\section{Da ferrovia ao museu, uma viagem pelas memórias que constroem as identidades}

de Peirópolis (1970-2018)

com ênfase na Ferrovia; Museu dos Dinossauros; chegada da Universidade Federal do Triângulo Mineiro - e impressões e sugestões socioculturais sobre o lugar.

Considerando tais transformações, pode-se visualizar Peirópolis como sendo uma sociedade moderna, apesar de ser lembrada pelos fósseis de dinossauros que habitaram o lugar há milhões de anos. Nesse sentido, Hall (2006) nos lembra que as sociedades modernas são por definição, sociedades de mudança constante, rápida e permanente. As diversas memórias temporalizadas pelos grupos de moradores entrevistados colaboraram para a conclusão de que a identidade é múltipla e, consequentemente, alterada pela comunidade. No entanto, há no bairro um aspecto identitário que sobressai aos outros, que é o senso de coletividade, este, sendo o fio condutor da história do lugar.

Além das fontes orais, a pesquisa foi subsidiada por documentos manuscritos e impressos. Embora tenham origens e intenções de produção diferentes, o tratamento destas fontes é semelhante, ou seja, se aproxima em sua metodologia. Ambas precisam de uma análise externa, isto é, de todo o contexto de produção para, em seguida, uma análise interna, de conteúdo. Bacellar (2018) demonstra a necessidade de contextualização do documento e da linguagem, sendo que, ausências ou ênfases dizem muito do interesse do autor ou particularidade/intencionalidade da fonte.

A temporalidade estabelecida para leitura das fontes documentais e impressas se dá entre os anos 1986 a 1988. Em seguida, o ano de 1992 também foi analisado na íntegra. O primeiro recorte trata dos esforços empreendidos para o impedimento da dinamitação dos fósseis e criação do Centro de Pesquisas Paleontológicas Llewellyn Ivor Price para o estudo dos materiais encontrados na região. O segundo momento 


\section{artigos}

\section{Karen Pereira Freitas Silva / Laura de Barros Pereira}

trata da conversão e inauguração do prédio da estação ferroviária desapropriada, em museu.

O trabalho de pesquisa documental realizado teve como norte a seguinte questão: Como Peirópolis aparece nas fontes? Conforme Certeau (2017, p.115), “compreender não é fugir para a ideologia, nem dar um pseudônimo ao que permanece oculto. É encontrar na própria informação histórica o que a tornará pensável". Partindo deste raciocínio, o objetivo era analisar a existência e forma de narrativas inerentes à Peirópolis.

As fontes documentais selecionadas para a pesquisa estavam disponíveis de modo físico no Arquivo Público de Uberaba (APU). Foram elencadas como fontes o Jornal Lavoura e Comércio e os livros de Atas da Câmara Municipal de Uberaba. Além destas, o diretor do CCCP, dr. Luís Carlos Ribeiro, disponibilizou seus arquivos pessoais para o trabalho de pesquisa.

O Jornal Lavoura e Comércio é um periódico muito importante, pois circulou ininterruptamente por mais de cem anos (1899-2003) em Uberaba e nas redondezas. Sendo esse o fator crucial para sua seleção enquanto fonte de pesquisa. Fundado por um grupo de produtores rurais de Uberaba e, posteriormente, assumido pela família de Quintiliano Jardim, o jornal foi um renomado veículo de massificação da notícia sobre a cidade e, consequentemente, sobre Peirópolis. Inicialmente, o Lavoura e Comércio propunha uma visão "neutra" e caráter meramente informativo sobre os eventos cotidianos, limitado ao formato de quatro páginas e periodicidade de publicação a cada três dias. Entretanto, seria uma ingenuidade no âmbito da pesquisa histórica, aceitar tal neutralidade autodeclarada em uma fonte confeccionada por uma elite agrária, com vistas a consolidar o periódico como fonte de expressão dos 


\section{artigos}

\section{Da ferrovia ao museu, uma viagem pelas memórias que constroem as identidades}

de Peirópolis (1970-2018)

acontecimentos da sociedade uberabense. No recorte temporal estabelecido para a pesquisa, a periodicidade das publicações já tinha se tornado diária.

Fator relevante a ser destacado sobre as peculiaridades da mídia periódica nas décadas de 1980 e 1990 é o fato do jornal não apontar os autores das notícias ou colunas. A luz desta dúvida, o funcionário do APU esclareceu às pesquisadoras que, mesmo em pleno século XX, os autores ou jornalistas não assinavam suas publicações por receio de represálias. Isso porque, no caso de denúncias, provocações ou críticas, eram ameaçados de inúmeras formas, chegando inclusive, a casos de homicídio.

Além do jornal, as Atas da Câmara Municipal de Uberaba também foram alvo da pesquisa. Dentro do mesmo recorte temporal, as atas foram disponibilizadas para manuseio físico. Esta fonte documental foi elencada no intuito de perceber a relação (ou não) do poder público com as transformações de Peirópolis. Elas são manuscritas e não possuem uma regularidade diária de trabalhos. São descritas as atividades e discussões dos vereadores em livros pautados e de folhas numeradas. São escritas de forma corrida e as separações entre datas é feita apenas por uma linha, ficando ao leitor a responsabilidade de conhecer a dinâmica vigente do processo de construção das reuniões, discussões, homenagens, deliberações e encerramentos.

O último espaço de pesquisa foi o arquivo do dr. Luís Carlos Ribeiro, diretor do Complexo Cultural e Científico de Peirópolis. Este arquivo estava organizado por tipo (cartas, memorandos, requisições, processos, etc), o que dificultou o trabalho, uma vez que não havia uma cronologia ou origem das fontes. Este espaço foi o último acessado para pesquisa e a utilização dele se deu em verificar a relação do Complexo Cultural e Científico de Peirópolis (CCCP), enquanto espaço da Universidade (UFTM) e da comunidade. 


\title{
artigos
}

\section{Karen Pereira Freitas Silva / Laura de Barros Pereira}

No trabalho de sentar e abrir pasta a pasta, emergiram os (as) historiadores(as) que confiam desconfiando. Isso porque, o exercício de selecionar dentre diversos tipos de fontes, qual a mais relevante, ou qual seria um contraponto importante na pesquisa, resultou desafiador. Contudo, neste arquivo, devido à dificuldade do deslocamento, o trabalho de seleção foi reduzido. Além disso, os documentos encontrados eram, em sua maioria, ligados unicamente às burocracias públicas. Correspondências, e-mails, boletins, relatórios, todos tratando do processo de pesquisa paleontológica nos últimos anos. Há troca de informações de pesquisas ou trânsito de estudantes nacionais e internacionais, acordos entre universidades argentinas para o desenvolvimento de pesquisas em Peirópolis, memorandos de recebimentos e prestação de contas de verbas destinadas à pesquisa e cópia do processo de tombamento da estação férrea convertida em museu. Entretanto, a documentação abordava a pesquisa paleontológica e o trânsito de pesquisadores, não tratando, especificamente, dos sujeitos da comunidade ou as relações entre eles.

\section{Sobre as fontes históricas}

\begin{abstract}
A partir do momento em que não nos resignamos mais a registrar [pura e] simplesmente as palavras das nossas testemunhas, a partir do momento em que tencionamos fazê-las a falar [, mesmo a contragosto], mais do que nunca impõe-se um questionário. Esta é, com efeito, a primeira necessidade de qualquer pesquisa histórica bem conduzida (BLOCH, 2001, p.78).
\end{abstract}

É a reflexão de Marc Bloch, ancorada nas metodologias de tratamento das fontes, que as hipóteses à problemática da pesquisa foram formuladas. Desta forma, elas foram pensadas de modo a criar uma cronologia da história de Peirópolis. Mesmo que o recorte temporal do trabalho esteja delimitado entre 1970 e 2018, foi preciso, em algumas situações, recuar um pouco mais no tempo para compreender o 


\section{artigos}

\section{Da ferrovia ao museu, uma viagem pelas memórias que constroem as identidades}

de Peirópolis (1970-2018)

significado das narrativas memoriais trazidas pelas entrevistas.

Uma memória citada na maioria das entrevistas é da escola do bairro, atualmente chamada Escola Municipal Frederico Peiró. Construída na década de 1910 por Frederico Peiró, foi fundada por ele com intuito de escolarizar os filhos de seus funcionários. É preciso contextualizar a conjuntura para compreender a importância da escolarização naquele momento. Isso porque, a cidade de Uberaba contava apenas com um grupo escolar para a cidade, enquanto Peirópolis, naquela época ainda chamada Paineiras, já tinha seu próprio espaço escolar,que atendia indiscriminadamente a todas as crianças da comunidade.

Ela foi feita por funcionários de Frederico Peiró, quando veio para cá, foram desbravando tudo, tinha muitos funcionários e as crianças não tinham escola né? Igual te falei aquele dia, foi interessante a ideia dele já querer dar o estudo para os filhos dos agregados dele. Aí foi quando fundou. Tem umas fotos dela antiga. Eu fui entrar aqui em 76. Na época era estadual. Aí depois ela passou, eu fiquei aqui de 76 a 79, com quarto ano. Depois fui para Ponte Alta, mas estava sempre acompanhando. Meus irmãos estudaram, aquela coisa toda. Em 88 que ela voltou para o município novamente e está até hoje. (SILVA, 2018).

Seja morando nas fazendas da região ou no próprio centro comercial do bairro, em que funcionava a estação ferroviária, as crianças frequentavam a escola que oferecia até o quarto ano primário. Além de estudar no bairro, duas moradoras foram docentes no lugar. A diretora se formou neste espaço escolar que dirige atualmente, com aparente satisfação e orgulho. Ela informa que a escola atende cerca de cem alunos e oferece até o nono ano do Ensino Fundamental. Com turmas pequenas, o grupo escolar desenvolve trabalhos e projetos com o desempenho de um colégio 


\section{artigos}

\section{Karen Pereira Freitas Silva / Laura de Barros Pereira}

privado, comenta a diretora.

Outras duas referências ao espaço escolar são marcantes nas entrevistas. Uma das antigas doceiras quando inquirida sobre uma memória saudosa do lugar se lembra instantaneamente dos tempos escolares. Segundo a moradora, porque ela era uma boa aluna. A segunda menção sobre o grupo escolar demonstra a integração social, coletividade e carinho sobre a escola. Todos os filhos dos moradores estudavam até o quarto ano primário. Conforme um dos entrevistados e atual presidente da Associação das Doceiras, havia outras escolas rurais na região, mas em Peirópolis havia mais cultura que as outras. Ele se lembra da importância do espaço escolar para os moradores e da neta de Frederico Peiró como professora.

Que a gente começou a estudar aqui porque quando a gente morava lá na companhia, lá em cima, lá não tinha cultura igual tinha aqui. Foi bão demais na época, a gente estudava aqui e a convivência com o povo era bão demais. Então era a dona Lia que era a professora e foi tudo mundo aqui. Ela que dava aula pra nós né? E era muito bom (CAETANO, 2018).

Um outro aspecto identitário de Peirópolis é o Espiritismo. Ele preponderou durante boa parte da história do bairro. Frederico Peiró, um materialista, conhece e se torna amigo pessoal de Eurípedes Barsanulfo (Médium pioneiro na prática do Espiritismo no Brasil). Assim, as reuniões espíritas no bairro são iniciadas. Esta dinâmica se deu ao longo de todo o século XX. Os encontros aconteciam nas casas dos moradores ou em um cruzeiro situado, atualmente, nos jardins do museu. Posteriormente, alguns imóveis foram convertidos em centros espíritas. Importante ressaltar que o lugar não possui uma capela ou igreja católica, diferentemente de outros bairros de Uberaba, que se organizam em torno destes espaços religiosos. 


\section{artigos}

\section{Da ferrovia ao museu, uma viagem pelas memórias que constroem as identidades}

de Peirópolis (1970-2018)

Este é um fator que demonstra um certo distanciamento cultural entre Peirópolis e a zona urbana de Uberaba.

Atualmente, o Espiritismo no bairro teve um recuo, depois da morte dos principais líderes que encabeçavam as reuniões, como Langerton Neves Cunha e o próprio Francisco Cândido Xavier, ambos médiuns espíritas renomados nacionalmente. Há também uma igreja evangélica no bairro e as manifestações religiosas coexistem pacificamente. Uma das entrevistadas comenta que, apesar de espírita, adora os padres e os evangélicos, sem que haja críticas. "Eu sou espírita, mas eu amo os padre, gosto deles, são meus amigos, e adoro a religião crente também, então toda religião é de Deus, desde que a gente pratica ela ou se não, não critica" (NICOLAUa, 2018).

Este respeito religioso é perceptível na fala de outra doceira que, sendo evangélica, produzia doces para Chico Xavier e era por ele muito elogiada. O médium de renome nacional frequentava mensalmente Peirópolis para as reuniões espíritas e comprava os doces da moradora.

Esta relação ecumênica em Peirópolis, tão ligada ao desenvolvimento espiritual, seja ele de qualquer natureza, também pode ser ilustrada na Fundação Peirópolis. Em parceria com a Prefeitura Municipal de Uberaba, ela iniciou, em 1995, um trabalho no intuito de promover o desenvolvimento humano, natural e científico. Amparada pela escola de Sathya Sai Baba e seus pilares norteadores: amor, paz, retidão, verdade e não violência, a fundação oferecia cursos de formação básica, extensionista e até pósgraduação. A área da Casa da Bolívia Alonso e dos Galpões da Máquina de Arroz imóveis tombados pelo Conselho do Patrimônio Histórico e Artístico de Uberaba nos anos 2000 - acolhiam os estudantes para os encontros e atividades, alimentação e 


\section{artigos}

\section{Karen Pereira Freitas Silva / Laura de Barros Pereira}

alojamento. Denominado campus Semente, as atividades ali perduraram até 2009.

Uma memória comum aos entrevistados e que perpassa décadas é a estação ferroviária em Peirópolis. Construída em uma conjuntura de progresso e modernização do Brasil, a linha férrea chegou ao bairro em 1889. A Companhia Mogiana intencionava levar os trilhos até Catalão (GO) e de lá seguir para Belém (PA). Entretanto, este entroncamento chegou apenas à cidade de Araguari (ESTAÇÕES FERROVIÁRIAS DO BRASIL, 2017).

Os moradores mais velhos relatam os tempos em que a ferrovia funcionava. Ela escoava a produção do bairro e transportava pessoas. Deste modo, além de movimentar economicamente o bairro, a ferrovia integrava aquele espaço rural à Uberaba e às pequenas cidades do entorno.

Era bão demais menina: o povo saia daqui e ia pra Uberaba, passava por Peirópolis aqui ó, ia Guaxima, passava por Conquista e chegava até Pedregulho, e voltava. Nóis ia muito, eu tinha naquela época 12 ou 13 anos, nóis andava isso aqui tudo; daqui Peirópolis, Conquista, Guaxima, eu conheço isso aí tudo (CAETANO, 2018).

Portanto, é possível inferir que, mesmo em face de um perfil agrário, esta comunidade não estava isolada. Ao contrário, pelos relatos das entrevistas, o trânsito de pessoas era intenso. Tanto que, no processo de tombamento e restauração da estação, foram mantidas as catracas que organizavam a circulação de pessoas e as placas em que se anotavam os horários dos trens. Entretanto, um acidente com vagões de passageiros e cargas em 28 setembro de 1970 abalou a comunidade e mudou de vez sua dinâmica econômica em torno da estação. 


\title{
artigos
}

\section{Da ferrovia ao museu, uma viagem pelas memórias que constroem as identidades} de Peirópolis (1970-2018)

A maioria dos entrevistados, mesmo os mais jovens, se lembram, nem que seja pelos testemunhos dos pais, da movimentação do lugar em função da ferrovia e do acidente que consequentemente encerrou o transporte férreo no bairro. Segundo um antigo morador, a Companhia Mogiana retomou a circulação dos trens pouco tempo depois do acidente, mas funcionou por cerca de dois ou três meses. Em seguida, o transporte foi finalizado e os trilhos foram arrancados.

\begin{abstract}
Nós andamos muito na ferrovia. Minha mãe morreu nesta ferrovia tem uns, ahh, uns 45 anos que ela pegava aqui a ferrovia e ia Jaguara, passava aqui e ia pra Jaguara e ela foi pra Conquista, na casa da tia dela, e antes de chegar na Conquista, na Guaxima, o trem estragou. E o trem parou, tava cheio de gente, dois vagão de cimento na frente e dois de gente atrás, porque o povo que lá ia pra Conquista ia no casamento, certo? E aí a máquina parou, dizem que o maquinista foi tentar dar um tranco nela, aí tinha muitas pessoas, até meu cunhado, irmão dela aí desceu, e os que não desceram do trem, o trem voltou, aí deve ter voltado uns 2 quilômetros né, Marcia? Eh, voltou e foi capotando e caiu dentro do Dourado, entornou o cimento e matou o povo quase tudo, a máquina veio e passou por cima daquilo tudo [incompreensível] e caiu dentro do Dourado. Foi uma coisa horrível (CAETANO, 2018).
\end{abstract}

Não foi encontrada documentação oficial que explicasse o encerramento da ferrovia em Peirópolis. Através das entrevistas, é possível pensar em algumas hipóteses. Inicialmente, as altas indenizações a serem pagas pela Companhia Mogiana em função das mortes e dos acidentados no descarrilamento. Além disso, o relevo montanhoso que, após o acidente, pode ter sido abandonado e a malha férrea remanejada para paisagens mais planas. Conforme a neta de Peiró, este evento desestruturou o transporte no bairro. Isso porque nem todos tinham veículos próprios. O transporte ferroviário era mais barato que o rodoviário, sendo que este era incipiente na época. 


\section{artigos}

\section{Karen Pereira Freitas Silva / Laura de Barros Pereira}

O fim da ferrovia mudou o panorama de Peirópolis. Aliado a este evento regional estão as transformações conjunturais do país, que buscavam elevar o Brasil à categoria de potência econômica, forjando a todo custo um sujeito tipicamente rural em consumidor urbano. A economia do lugar girava em torno da atividade agrícola das fazendas da região e da exploração do calcário. Com o fim da atividade ferroviária, houve a migração de jovens habitantes da comunidade para espaços urbanos mais próximos em busca de oportunidades de estudo e trabalho, uma vez que obairro teve suspenso seu principal meio de deslocamento de pessoas e mercadorias.

Quando os primeiros fósseis de dinossauros foram encontrados, apesar da relevância do achado, a empresa de calcário continuou a atuar na extração mineral. Ainda não havia um espaço para pesquisa e análise dos materiais recolhidos nas primeiras escavações. Iniciativas independentes levavam o material fóssil eventualmente para os centros de pesquisa nacionais, como a Universidade Federal do Rio de Janeiro.

Em meados dos anos 1980, por iniciativa empreendida pela comunidade local, houve um processo judicial contra a empresa de calcário para barrar a dinamitação das rochas e a destruição do patrimônio paleontológico. Há uma reflexão importante neste processo histórico e que atravessa não somente as memórias dos entrevistados, mas se materializa na identidade publicizada pelos locais. Os moradores de Peirópolis foram afetados pelo encerramento da exploração do calcário, uma vez que esta representava boa parte da fonte de trabalho na região. A comunidade compreendeu a relevância da conservação do patrimônio paleontológico do lugar e a possibilidade de prosperidade econômica através da formatação do bairro para um espaço de turismo. 


\title{
artigos
}

\section{Da ferrovia ao museu, uma viagem pelas memórias que constroem as identidades de Peirópolis (1970-2018)}

As pessoas abraçaram a causa e, consequentemente, passaram a lutar pela instituição de um espaço de pesquisa e conservação dos fósseis, além de um museu para expô-los. Esta manifestação de coletividade no bairro, na figura da Associação dos Amigos do Sítio Paleontológico de Peirópolis, foi identificada nas fontes pesquisadas. A iniciativa da comunidade foi observada nas Atas da Câmara Municipal de Uberaba e nas entrevistas com os moradores.

\begin{abstract}
Professor Bethoveen Teixeira (Diretor do Museu Paleontológico de Peirópolis): "Nós estamos na etapa inicial, fazendo o trabalho de escavação. A segunda etapa é a implantação e o apoio para instalar este centro. Nós desapropriamos, por iniciativa pública, uma área de noventa metros quadrados que está em fase final de negociação com a Fepasa já liberado pelo juiz, dando a nós o termo de posse para que nós pudéssemos iniciar imediatamente a restauração da estação e começar o centro, dependendo apenas do apoio dos políticos. Vereador Antônio Bernardes (hipotecando solidariedade aos visitantes, enfatizou): "Nós não temos, para apresentar aos nossos visitantes nada de efetivamente interessante, como ponto turístico. Resultando bem estas pesquisas de Peirópolis teremos como atrair pessoas para que aqui nos venham visitar" (Atas da Câmara Municipal de Uberaba, 09 de novembro de 1987, p.16-17).
\end{abstract}

A mobilização da comunidade, desde a judicialização para o fim da exploração do calcário, passando pelo tombamento da estação ferroviária e organização desta em espaço museológico, aparece pontualmente e superficialmente nas Atas da Câmara Municipal. Esse silenciamento do poder público em meio a toda esta efervescência tocou as pesquisadoras. De acordo com Bloch,

A despeito do que às vezes parecem imaginar os iniciantes, os documentos não surgem, aqui ou ali, por efeito [de não se sabe] qual misterioso decreto dos deuses. Sua presença ou ausência em tais arquivos, em tal biblioteca, em tal solo deriva de causas humanas que não escapam de modo algum à análise (BLOCH, 2001, p.83). 


\section{artigos}

\section{Karen Pereira Freitas Silva / Laura de Barros Pereira}

O silêncio das autoridades sobre as inquietações em Peirópolis era, para as pesquisadoras, uma incongruência. Esta angústia foi se dissipando à medida em que as entrevistas aconteciam. Ao longo das falas dos moradores, quando as transformações das décadas de 1980 e 1990 eram abordadas, em diversas vezes, os entrevistados demonstravam o envolvimento da comunidade. Ela trocou a estabilidade empregatícia no calcário para o anseio de um espaço turístico e paleontológico, apropriando-se de uma causa patrimonial, de um bem cultural, forjando o entendimento e a identidade de si como terra dos dinossauros.

Ademais, o desinteresse do poder público no bairro é mencionado nas entrevistas, ora de forma velada, ora escancarada. O exemplo recorrente na fala dos moradores é a questão da pavimentação e do calçamento do bairro: tanto turistas quanto moradores reclamavam da terra e da poeira. O calçamento foi iniciado, porém, ainda está por terminar. O descaso público é um aspecto relevante para a comunidade pois o bairro é um importante ponto turístico de Uberaba, mas não é tratado com esta consideração.

Além disso, o Jornal Lavoura e Comércio, quando trata de Peirópolis, traz avante apenas as descobertas paleontológicas, visitas ou exposições no exterior. O foco é direcionado para a paleontologia. O envolvimento da comunidade para que estas descobertas e pesquisas rendessem frutos não são mencionados nas fontes impressas.

Peirópolis voltou a prosperar com a instituição do Museu dos Dinossauros, em 1992, no prédio da antiga estação ferroviária, que foi tombada pelo Conselho de Patrimônio Histórico e Artístico de Uberaba (CONPHAU), nos anos 2000. Turistas curiosos e ônibus escolares de toda parte iam a Peirópolis conhecer os fósseis. Junto 


\title{
artigos
}

\section{Da ferrovia ao museu, uma viagem pelas memórias que constroem as identidades}

de Peirópolis (1970-2018)

a esta transformação e às demandas urbanas que ela exige, o bairro recebeu pavimentação nas ruas, energia elétrica, telefone público, sistemas de água e esgoto, etc.

\begin{abstract}
... como se diz, quando veio os primeiros ossos que começou a vim tudo isso pra Peirópolis, mesmo que não tinha asfalto vinha muita gente... agora que diminuiu um pouco, porque muita gente já conhece... mas antigamente ô.. eu não trabalhava no museu, a minha irmã trabalhou, nossa vinha gente de escola, mas vem da escola até hoje, agora nas férias, principalmente, agora as férias de janeiro vem bastante gente, cê chega lá cê assina um livro lá cê vai ver gente de vários lugares (MORAISa, 2018).
\end{abstract}

As mulheres da comunidade aproveitaram o movimento e vendiam seus produtos caseiros. A famosa casinha de doces - prédio tombado como Casa do Vigia ou Portador - é uma pequena construção de tijolinhos à vista. O espaço foi cedido às doceiras do bairro para que elas comercializassem os doces caseiros com os turistas. Porém, quando foi instituída a Associação Comunitária Peirópolis, houve algumas dissidências. O grupo não se manteve o mesmo e alguns integrantes pararam de produzir ou passaram para uma produção independente. Atualmente, a Associação das Doceiras comercializa os produtos na cozinha industrial anexa à Casa do Turista, antiga casa de Frederico Peiró, que foi tombada e restaurada. Há também outros pontos de venda de doces espalhados pelo bairro.

Além dos doces, outro aspecto da gastronomia é muito importante para o turismo no bairro. Existem vários restaurantes de comida típica mineira que servem os turistas. Assim, como a movimentação é intensa nos fins de semana, esses estabelecimentos funcionam apenas aos sábados e domingos. Por este fator, 


\title{
artigos
}

\section{Karen Pereira Freitas Silva / Laura de Barros Pereira}

Peirópolis possui duas facetas: uma bem pacata e tranquila ao longo da semana e ativo movimento nos finais de semana.

A Universidade Federal do Triângulo Mineiro (UFTM) chegou a Peirópolis em 2010. À princípio, a relação com a comunidade foi delicada. A gestão universitária passou a tomar conta do Museu dos Dinossauros e prédios anexos, antes sob responsabilidade da prefeitura, mas com participação ativa da comunidade.

\begin{abstract}
A comunidade sentiu o impacto sim. Eu lembro muito bem na época, porque era tudo novo ainda mesmo porque estava saindo o museu, era aquela questão, a gente sentia segurança por ser prefeitura aquela coisa. E quando a UFTM chegou a gente não sabia até que ponto podia sentir segurança. Acho que é uma questão de segurança mesmo. $E$, às vezes, hoje eu vejo com outros olhos a UFTM [...] Agora quanto aos moradores, na época sofreram muito impacto sim. Mesmo porque, a comunidade pode ser pacata, mas ela fica antenada, sabe. Ela já fica meio que assim sabe. Aí o pessoal chega "Vamos fazer isso e pronto", "eu posso fazer isso e pronto", aí sentiram... (SILVA, 2018).
\end{abstract}

Os imóveis, além do prédio da estação convertida em museu, também são tombados pelo CONPHAU e reúnem a Casa de Hóspedes ou Hospedaria, convertida em alojamento para estudantes e pesquisadores, a Casa do Trole e Casa do Vigia/Portador que funcionam para armazenamento de materiais de limpeza e jardinagem. A transição município/federação não foi discutida nem justificada com a comunidade que cooperou para a instituição e desenvolvimento dos espaços. Este desconforto tem diminuído ao longo dos anos, já que, através da Universidade, há uma tarefa intelectual de pesquisadores e estagiários no lugar. Existe também o trabalho físico de conservação e modernização dos jardins e do museu. Neste sentido, além de movimentar o lugar, alguns dos terceirizados que trabalham na UFTM em Peirópolis são moradores do bairro. 


\section{artigos}

\section{Da ferrovia ao museu, uma viagem pelas memórias que constroem as identidades}

de Peirópolis (1970-2018)

Apesar de gostarem da comunidade pequena e tranquila, os moradores veem com bons olhos a movimentação do turismo e sugerem melhorias para intensificá-lo. É importante explicitar que há duas facetas na dinâmica do bairro. Durante a semana, Peirópolis é pacata, um típico bairro rural. O maior movimento neste período é o de ônibus escolares que visitam e exploram os espaços museológicos. Os restaurantes e estabelecimentos ficam fechados, exceto a Casa do Turista. Entretanto, aos finais de semana, o cenário do bairro se transforma. Há um trânsito intenso de visitantes que aproveitam tanto os espaços paleontológicos, quanto a gastronomia dos restaurantes e doces, além de desfrutarem do bucolismo do lugar. Embora não queiram sair do bairro em função da segurança e pacificidade, o movimento dos finais de semana agrada a comunidade, tanto aos comerciantes, quanto aos moradores.

A partir destes marcos memoráveis da história de Peirópolis, é possível conjecturar algumas identidades que caracterizam as relações socioculturais no bairro. A mais enfática delas é o senso de coletividade. Ela é o fio condutor da história do lugar, estando presente em diversas falas nas entrevistas. A união da comunidade é citada desde os tempos em que as mulheres se revezavam para lavar roupas nas cisternas, sendo que, as que moravam mais longe utilizavam primeiro a água. Assim, terminariam a lavação mais cedo para percorrerem o caminho até suas residências. A disseminação do conhecimento na produção dos doces também é um exemplo. As doceiras ensinavam umas às outras o processo produtivo e dividiam coletivamente o trabalho de produção, organização e vendas na casinha de doces até a instituição da Associação das Doceiras.

Outro momento é o trabalho de conscientização dos moradores e a sua união na luta para a preservação dos fósseis, mesmo quando isso representou o 


\section{artigos}

\section{Karen Pereira Freitas Silva / Laura de Barros Pereira}

desemprego para muitas famílias que dependiam da exploração do calcário. A Associação dos Amigos do Sítio Paleontológico de Peirópolis talvez seja o mais destacado emblema deste senso de coletividade. Tendo em vista o silêncio das autoridades públicas sobre as transformações de Peirópolis, o grupo aparece nas fontes no momento de luta pela preservação dos fósseis e na criação do museu e espaço de pesquisas paleontológicas.

O senso de coletividade se amarra em outra identidade latente em Peirópolis que é a religiosidade. Desde a chegada de Frederico Peiró até os trabalhos de Langerton Neves e Chico Xavier, o Espiritismo preponderou no lugar. Porém, mesmo com seu protagonismo, outras manifestações religiosas coexistiram e coexistem em perfeita harmonia no bairro. Apesar de serem diferentes práticas religiosas, espíritas, católicos e protestantes se relacionam respeitosamente.

Outro fio da trama identitária de Peirópolis é o pertencimento aliado à consciência de agentes da história. Esta faceta se manifesta através das memórias que os entrevistados têm da história e das transformações que aconteceram no bairro. Mesmo que alguns deles não tenham vivenciado os fatos, eles foram perpetuados através da oralidade. Alguns exemplos são as atividades da ferrovia e a visão progressista de Frederico Peiró.

Entretanto, cabe aqui pontuar, novamente, a metodologia inerente às fontes orais. As memórias podem ser ressignificadas, ou seja, elas podem ser memórias de um passado, mas reconfiguradas com percepções do presente. Desta perspectiva, mesmo que os eventos não tenham sido vivenciados por todos os sujeitos, a apropriação das memórias é justificada e reforçada nas conquistas da Associação dos Amigos do Sítio Paleontológico de Peirópolis. A luta e vitória dos moradores no que 


\section{artigos}

\section{Da ferrovia ao museu, uma viagem pelas memórias que constroem as identidades}

de Peirópolis (1970-2018)

tange à conservação dos fósseis e tombamento da estação férrea, convertida em museu, empoderou a comunidade. Que se percebeu dona e responsável por este patrimônio paleontológico, histórico e cultural. Tomando consciência da importância deste legado para a retomada de Peirópolis como um bairro próspero, tal qual as memórias sugerem que o lugar vivenciou na época de Peiró e da ferrovia. Logo, os moradores compreendem a si mesmos como sujeitos da sua própria história.

Por fim, há uma identidade de Peirópolis que talvez seja a que menos se manifesta: a construção de conhecimentos. Em certa medida, ela se consolida a partir da chegada da Universidade (UFTM) no bairro, mas que ainda é desvanecida. O apreço pelo conhecimento se evidencia na iniciativa de Frederico Peiró em construir uma escola inclusiva, lá em meados de 1910, que permanece em pleno funcionamento na atualidade. Em seguida, a descoberta dos fósseis nos anos 1940 iniciou um trânsito notável de estudiosos e especialistas, o que era incomum em zonas rurais. Alguns moradores, inclusive, foram treinados para o trabalho e manuseio das peças fossilíferas, devido à grande demanda de materiais encontrados.

A Fundação Peirópolis também é uma expressão da identidade cultural e científica do bairro, uma vez que promoveu diversos cursos e encontros no sentido de formação intelectual e humana. Como a paleontologia, a Fundação atraia muitas pessoas de diferentes lugares e formações. O Museu dos Dinossauros e o Complexo Científico e Cultural de Peirópolis, bem como a visitação frequente de alunos de diversos lugares da região também são indicadores de que o bairro é um espaço de aprendizagem constante. Por último, a presença da Universidade Federal do Triângulo Mineiro ratifica a identidade de Peirópolis como um espaço de construção de conhecimentos. 


\section{artigos}

\section{Karen Pereira Freitas Silva / Laura de Barros Pereira}

Portanto, é perceptível que as identidades no bairro são múltiplas e possuem pontos de conexão. O processo histórico do lugar, ora em sua pluralidade, ora em suas singularidades, proporciona a construção das identidades constatadas neste estudo. A estação ferroviária que se converte em museu paleontológico é um pilar histórico do qual emergem e se configuram as identidades. Algumas manifestas e consolidadas, como é o caso da Paleontologia. As demais são nuançadas no cotidiano dos moradores, em suas relações pessoais, culturais, de trabalho e assim por diante. Nos meandros das memórias, as identidades de Peirópolis se constituem. Elas se perpassam e se configuram. Para isso, os moradores e agentes da História de Peirópolis têm sapiência para lidar com tempos efêmeros de identidades descentradas.

\section{Fontes Documentais e Impressas}

Arquivo Público de Uberaba. Jornal Lavoura e Comércio. Uberaba. 1986, 1987, 1988 e 1992. Diário.

Arquivo Público de Uberaba. Atas da Câmara Municipal de Uberaba, dos anos 1986, 1987, 1988 e 1992.

A MEMORIA Benemérita de Frederico Peiró. Jornal Lavoura e Comércio. Uberaba,19 dez de 1915. Disponível em:

http://app.codiub.com.br/drive_root/lavouraecomercio/edicoes/edicao01830.pdf. Acesso em: 01 ago 2019.

DESESPERO e morte na Serra dos Dourados. Jornal Lavoura e Comércio. Uberaba, 28 set. 1970.

\section{Fontes Orais}

CAETANO, N. P.. Entrevista concedida às autoras, Uberaba, 2 out. 2018. 


\section{artigos}

Da ferrovia ao museu, uma viagem pelas memórias que constroem as identidades de Peirópolis (1970-2018)

MORAISa, F. de. Entrevista concedida às autoras, Uberaba, 5 jul. 2018.

MORAISb, I. I.. Entrevista concedida às autoras, Uberaba, 13 set. 2018.

NICOLAUa, D.. Entrevista concedida às autoras, Uberaba, 28 ago. 2018.

NICOLAUb, M.. Entrevista concedida às autoras, Uberaba, 28 ago. 2018.

SILVA, S. M. da. Entrevista concedida às autoras, Uberaba, 27 set. 2018.

Referências Bibliográficas

ALBERTI, V. Histórias dentro da História. In: PINSKY, C. B. Fontes Históricas. 3ed. São Paulo: Contexto, 2018. p.155-202.

BACELLAR, C. Uso e mau uso dos arquivos. In: PINSKY, C. B. Fontes Históricas. 3ed. São Paulo: Contexto, 2018. p. 23-79.

BLOCH, M. Apologia da História ou o Ofício do Historiador. Rio de Janeiro: Zahar, 2001.

CERTEAU, Michel de. A Escrita da História. $3^{\mathrm{a}}$ ed. Rio de Janeiro: Forense-Universitária, 2017.

CIA. Mogiana de Estradas de Ferro (1889-1971) FEPASA (1971-1976). Estações

Ferroviárias do Brasil, 05 de out. 2017. Disponível em:

http://www.estacoesferroviarias.com.br/mogiana_triangulo/peiropolis.htm. Acesso em 01 ago. 2019.

HALL, S. A identidade cultural na pós-modernidade. 11ed. Rio de Janeiro: DP\&A, 2006.

OLIVEIRA, P.R. Para além do Rio Grande: os impactos da economia paulista sobre o Triângulo Mineiro. História, 2008, v. 27, p. 2013-223.

RIBEIRO, L. C. B. Geoparque Uberaba - Terra dos Dinossauros do Brasil. 2014. Tese (Doutorado em Geologia) - Universidade Federal do Rio de Janeiro, Rio de Janeiro, 2014. 


\section{artigos}

Karen Pereira Freitas Silva / Laura de Barros Pereira

RIBEIRO, L.C.B; CARVALHO, I.S. Sítio Peirópolis e Serra da Galga, Uberaba, MG - Terra dos Dinossauros do Brasil. Sítios Geológicos e Paleontológicos do Brasil. $3^{\mathrm{a}}$ ed. 2007, v. 3, p. 1-13.

RICOEUR, P. Da Memória e da Reminiscência: Memória Pessoal, Memória Coletiva. In: A memória, a história, o esquecimento. Campinas, SP: Editora da Unicamp, 2007, p. 105-142. 